\title{
Synthesis, redox properties, and basicity of substituted 1-aminoanthraquinones: spectroscopic, electrochemical, and computational studies in acetonitrile solutions
}

\author{
D. Zarzeczańska $\cdot$ P. Niedziałkowski $\cdot$ \\ A. Wcisło $\cdot$ L. Chomicz $\cdot$ J. Rak $\cdot$ T. Ossowski
}

Received: 24 July 2013/ Accepted: 10 August 2013/Published online: 30 August 2013

(C) The Author(s) 2013. This article is published with open access at Springerlink.com

\begin{abstract}
Amino-, 1-ethylamino-, and 1-(diethylamino)anthraquinone were characterized by UV-Vis spectroscopy, acid-base titration, electrochemical methods, and quantumchemical $(\mathrm{QM})$ calculations at the $\mathrm{B} 3 \mathrm{LYP} / 6-31++\mathrm{G}^{* *}$ level. Acid-base titration and the relative differences between the free energies of the basic and acidic forms of the studied species show that 1-(diethylamino)anthraquinone is the strongest base in an acetonitrile solution. Moreover, the structural differences between the B3LYP-optimized neutral and protonated anthraquinones, notably the presence or the absence of internal hydrogen bonds, account well for the sequence of the measured/calculated basicity. The basicity of the investigated compounds strongly influences their electrochemical properties in acetonitrile. Indeed, the cyclic voltammograms of 1-aminoanthraquinone and 1-(ethylamino)anthraquinone display two well-resolved reduction waves that indicate a two-step reduction process (EE mechanism). On the other hand, the electroreduction of 1-(diethylamino)anthraquinone becomes complicated by the interaction of its reduced forms with traces of water present in an acetonitrile solution (ECE mechanism). The mechanism of this reaction is proposed, and its possibility to occur is examined based on QM calculations.
\end{abstract}

Electronic supplementary material The online version of this article (doi:10.1007/s11224-013-0332-z) contains supplementary material, which is available to authorized users.

D. Zarzeczańska $(\varangle) \cdot$ P. Niedziałkowski · A. Wcisło ·

L. Chomicz - J. Rak - T. Ossowski

Faculty of Chemistry, University of Gdańsk, Wita Stwosza 63, 80-952 Gdańsk, Poland

e-mail:dorota@chem.univ.gda.pl
Keywords Monoamino-9,10-anthraquinone derivatives · Acid-base properties · UV-Vis spectrophotometry - Spectrophotometric titrations . Cyclic voltammetry $\cdot$ DFT calculations

\section{Introduction}

Quinones are biologically important class of compounds occurring in plants, living organism, and in inanimate world. Many derivatives containing a quinone fragment in their structure exhibit a significant biological activity [1,2]. For instance, in the respiratory enzymes quinone derivatives constitute a part of the electron-transfer chain [3]. Moreover, they are used as defensive compounds by some leaf beetles and also exhibit antitermitic activity $[4,5]$.

A number of previous studies have shown that the redox properties of anthraquinones are directly connected to their acid-base properties [6]. It is well known that under protic condition, the reduction of quinones produces corresponding hydroquinones $[7,8]$.

$\mathrm{Q}+2 \mathrm{H}^{+}+2 \bar{e}=\mathrm{H}_{2} \mathrm{Q}$

In an aqueous solution, the individual one-electron processes comprised in reaction (1) usually occur as a single two-electron reduction process. However, in aprotic media, the reduction of quinones takes place in two wellresolved steps: the first one corresponds to the formation of the $\mathrm{Q}^{-\bullet}$ radical anion, and at the more negative potential, the closed-shell dianion, $\mathrm{Q}^{2-}$, is formed (see eqs. 2 and 3 ):

$\mathrm{Q}+\bar{e}=\mathrm{Q}^{-\bullet}$

$\mathrm{Q}^{-\bullet}+\bar{e}=\mathrm{Q}^{2-}$

The occurrence of two well-resolved reduction waves on a cyclic voltammogram is dubbed the EE mechanism 
$[9,10]$. However, in the literature reports on the electrochemical reduction of quinones in polar, aprotic solvents, the EE mechanism is very often claimed to be not operative [11].

While studying various methyl derivatives of aminoanthraquinones in a methanol solution, Peters and Sumner proved that the difference in their basicity amounts to as much as around four $p K$ units [12]. Such a significant difference in basicity was attributed to the possibility of the formation of a hydrogen bond between the proton of the amino group and the oxygen of the quinone carbonyl function only in some of the studied derivatives $[12,13]$.

The protonation of 1-amino substituent changes electron density on the nitrogen atom, which leads to the reduction of the molar absorption coefficient of the band appearing at about $500 \mathrm{~nm}$ for the neutral anthraquinone [13, 14]. This phenomenon allows the dissociation constants of aminoanthraquinone derivatives to be determined spectrophotometrically.

In this article, the acid-base properties of 1-aminoanthraquinone $\left(\mathrm{AQNH}_{2}\right)$, 1-(ethylamino)anthraquinone (AQNHEt), and 1-(diethylamino)anthraquinone $\left(\mathrm{AQNEt}_{2}\right)$ (for structures see Fig. 1) in an acetonitrile solution were studied experimentally by electrochemical and UV-Vis spectroscopic methods.

The measured $p K a$ constants were compared with the quantum-chemically derived differences in the stability of the neutral and protonated forms in acetonitrile for all the studied systems. Finally, differences in the behaviors of $\mathrm{AQNH}_{2}$ and $\mathrm{AQNHEt}$ and that of $\mathrm{AQNEt}_{2}$ in cyclic voltammetry, performed in the acetonitrile solution, have been interpreted in terms of the reaction of the fully reduced $\mathrm{Q}^{2-}$ form of the latter compound with traces of water. This supposition has been conformed in cyclic voltammetry experiments for acetonitrile solutions containing the controlled concentrations of water, and with the quantum chemical (QM) thermodynamic characteristics of the reaction of anthraquinone dianions with water.
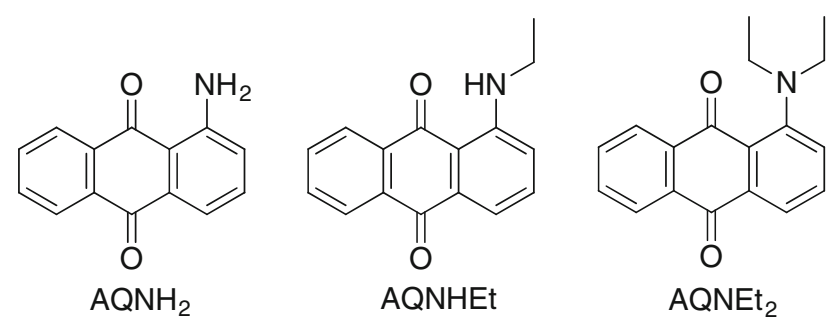

Fig. 1 The structures of studied anthraquinone derivatives: $\mathrm{AQNH}_{2}$, AQNHEt, and AQNEt ${ }_{2}$

\section{Materials and methods}

Materials

All commercially available reagents and solvents were purchased from Sigma Aldrich and used without further purification. Only acetonitrile (HPLC grade, $>99.9 \%$ ) was dried with molecular sieves ( $4 \AA$ ) before usage. ${ }^{1} \mathrm{H}$ and ${ }^{13} \mathrm{C}$ NMR spectra were recorded on a Varian, Mercury-400 spectrometer 400 and $100 \mathrm{MHz}$, respectively, with TMS as an internal reference and $\mathrm{CDCl}_{3}$ as a solvent. IR spectra were recorded on a Bruker IFS66 spectrometer as $\mathrm{KBr}$ pellets. MALDI mass spectra were recorded on a Biflex III MALDI-TOF mass spectrometer. Elemental analyses were recorded on a Carlo-Erba CHNS-O EA1108 elemental analyzer. The purity of the obtained compounds was checked by Shimadzu HPLC system LC-20A Series using a Phenomenex Luna $\mathrm{C}_{8}$ column $(100 \AA, \quad 3 \mu \mathrm{m}$, $150 \times 4.60 \mathrm{~mm})$. The solvent system contained $0.1 \%$ TFA in water (solvent $\mathrm{A}$ ) and $100 \%$ acetonitrile (solvent B). A linear gradient was applied from $1 \% \mathrm{~A}$ to $100 \% \mathrm{~B}$ for $30 \mathrm{~min}$ at a flow rate of $1.0 \mathrm{~mL} / \mathrm{min}$. Detection of the peaks was achieved by a UV detector at $254 \mathrm{~nm}$.

$\mathrm{AQNH}_{2}$ was purchased from Sigma Aldrich and used without further purification, while AQNHEt and $\mathrm{AQNEt}_{2}$ were synthesized as described below.

Synthesis

\section{AQNHEt}

Ethylamine (185 mg, $4.121 \mathrm{mmol})$ was added to a mixture of 1-chloroanthraquinone $(500 \mathrm{mg}, 2.060 \mathrm{mmol})$ and cesium carbonate $(1.342 \mathrm{~g}, 4.121 \mathrm{mmol})$ in $200 \mathrm{~mL}$ of toluene (Scheme 1). The reaction mixture was stirred at $80{ }^{\circ} \mathrm{C}$ for $48 \mathrm{~h}$ under argon. The reaction mixture was cooled to room temperature (RT), and the solvent was removed under reduced pressure. The residue was dissolved in dichloromethane $(200 \mathrm{~mL})$ and washed with water $(2 \times 100 \mathrm{~mL})$. The organic phase was dried over anhydrous magnesium sulfate, and the solvent was removed in vacuo. The crude product was purified by flash column chromatography using silica gel and mixture of dichloromethane and methanol (95:5) as eluent to give $360 \mathrm{mg}$ of desired compound $(69 \%)$ as red solid. $\mathrm{mp}$ $165{ }^{\circ} \mathrm{C}$; IR (KBr) 3424, 2925, 1677,1630, 1593, 1575, $1510,1313,1269,1150,1071,1009,801,735,725$, 703,$646 ;{ }^{1} \mathrm{H} \mathrm{NMR}\left(\mathrm{CDCl}_{3}, 400 \mathrm{MHz}\right) \delta 1.39-1.43(\mathrm{t}, 3 \mathrm{H}$, $\left.\mathrm{NH}-\mathrm{CH}_{2}-\mathrm{CH}_{3}, J=7.2 \mathrm{~Hz}\right), 4.02-4.04\left(\mathrm{p}, 2 \mathrm{H}, \mathrm{NH}-\mathrm{CH}_{2}-\right.$ $\mathrm{CH}_{3}, J_{1}=6.2 \mathrm{~Hz}, J_{1}=7.2 \mathrm{~Hz}, J_{1}=4.8 \mathrm{~Hz}, J_{2}=6.7$ $\mathrm{Hz}, J_{2}=7.2 \mathrm{~Hz}, J_{2}=6.0 \mathrm{~Hz}, J_{3}=6.6 \mathrm{~Hz}, J_{3}=6.9 \mathrm{~Hz}$, $\left.J_{4}=6.7\right), 7.54-7.56 \quad(\mathrm{~d}, \quad 1 \mathrm{H}, \quad \mathrm{H}-2 \quad \mathrm{Ar}, \quad J=7.6 \mathrm{~Hz})$, 7.58-7.61 (dd, $\left.1 \mathrm{H}, \mathrm{H}-4 \mathrm{Ar}, J_{1}=1.2 \mathrm{~Hz}, J=7.2 \mathrm{~Hz}\right)$, 
7.68-7.72 (dt, 1H, H-3 Ar, $J_{1}=1.2 \mathrm{~Hz}, J_{2}=7.2 \mathrm{~Hz}$, $\left.J_{2}=7.8 \mathrm{~Hz}, J_{3}=7.5 \mathrm{~Hz}\right), 7.74-7.78(\mathrm{dt}, 1 \mathrm{H}, \mathrm{H}-6 \mathrm{Ar}$, $\left.J_{1}=1.2 \mathrm{~Hz}, J_{1}=2.0 \mathrm{~Hz}, J_{2}=7.4 \mathrm{~Hz}\right), 7.78-7.82(\mathrm{dt}$, $1 \mathrm{H}, \mathrm{H}-7$ Ar, $J_{1}=1.2 \mathrm{~Hz}, J_{1}=2.0 \mathrm{~Hz}, J_{2}=7.6 \mathrm{~Hz}$ ), 8.23-8.25 (dd, $1 \mathrm{H}, \mathrm{H}-5 \mathrm{Ar}, J_{1}=1.2 \mathrm{~Hz}, J_{1}=1.6 \mathrm{~Hz}$, $\left.J_{2}=7.4 \mathrm{~Hz}\right), 8.29-8.30\left(\mathrm{dd}, 1 \mathrm{H}, \mathrm{H}-8 \mathrm{Ar}, J_{1}=1.6 \mathrm{~Hz}\right.$, $\left.J_{2}=7.6 \mathrm{~Hz}\right), 9.66\left(\mathrm{~s}, \quad 1 \mathrm{H}, \quad \mathrm{NH}-\mathrm{CH}_{2}-\mathrm{CH}_{3}\right) ;{ }^{13} \mathrm{C} \mathrm{NMR}$ $\left(\mathrm{CDCl}_{3}, 100 \mathrm{MHz}\right) \delta 14.5 ; 36.5\left(\mathrm{CH}_{2}\right) ; 115.7,118.03$, 126.8, 126.9, 127.01, 127.8, 133.0, 133.8, 134.13, 134.7, 135.5, 135.5 (CH, Ar); 182.1, 183.5 (2C=O, Ar); MaldiTof $m / z \quad 252.2 \quad[\mathrm{M}+\mathrm{H}]^{+} \quad(\mathrm{MW}=251.280) ; \quad$ Anal. $\left(\mathrm{C}_{16} \mathrm{H}_{13} \mathrm{NO}_{2}\right)$ : Calcd. C, 76.48; H, 5.21; N, 5.57; found $\mathrm{C}$, 76.44; H, 5.22; N, 5.60; Purity (HPLC): $98.9 \%$. $t_{\mathrm{R}}=17.95 \mathrm{~min}$.

\section{$\mathrm{AQNEt}_{2}$}

Diethylamine (605 mg, $8.264 \mathrm{mmol}$ ) was added to a solution of 1-chloroanthraquinone (500 mg, $2.060 \mathrm{mmol}$ ) in $150 \mathrm{~mL}$ of toluene (Scheme 2). The reaction mixture was thoroughly degassed by passing a stream of argon. The reaction mixture was heated at $100{ }^{\circ} \mathrm{C}$ for $24 \mathrm{~h}$. After cooling to RT, the solvent was evaporated at reduced pressure. The residue was dissolved in dichloromethane $(200 \mathrm{~mL})$, washed with water $(2 \times 100 \mathrm{~mL})$, and dried over anhydrous magnesium sulfate. The organic phase was evaporated at reduced pressure. The crude product was purified by flash column chromatography using silica gel and dichloromethane as eluent to give $520 \mathrm{mg}$ of product (90\%) as red solid. mp 98-100 ${ }^{\circ} \mathrm{C}$; IR (KBr) 3434, 2967, 1662, 1643, 1577, 1452, 1426, 1316, 1253, 1157, 1051, 985, 896, 797, 736, 718, 663620; ${ }^{1} \mathrm{H}$ NMR $\left(\mathrm{CDCl}_{3}\right.$, $400 \mathrm{MHz}) \quad \delta \quad 1.13-1.17 \quad\left(\mathrm{t}, \quad 6 \mathrm{H}, \quad \mathrm{NH}-\mathrm{CH}_{2}-\mathrm{CH}_{3}\right.$,
$\left.J_{1}=7.2 \mathrm{~Hz}, J_{1}=6.8 \mathrm{~Hz}, J_{2}=7.0 \mathrm{~Hz}\right), 3.35-3.41(\mathrm{q}, 4 \mathrm{H}$, $\mathrm{NH}-\mathrm{CH}_{2}-\mathrm{CH}_{3}, J_{1}=7.2 \mathrm{~Hz}, J_{1}=6.8 \mathrm{~Hz}, J_{2}=7.2 \mathrm{~Hz}$, $\left.J_{2}=7.0 \mathrm{~Hz}, J_{3}=7.1 \mathrm{~Hz}\right), 7.54-7.56(\mathrm{dd}, 1 \mathrm{H}, \mathrm{H}-2 \mathrm{Ar}$, $\left.J_{1}=0.8 \mathrm{~Hz}, J=8.4 \mathrm{~Hz}\right), 7.52-7.56(\mathrm{t}, 1 \mathrm{H}, \mathrm{H}-3 \mathrm{Ar}$, $\left.J_{1}=7.8 \mathrm{~Hz}, J_{1}=8.2 \mathrm{~Hz}, J_{2}=8.0 \mathrm{~Hz}\right), 7.67-7.71(\mathrm{dt}$, $1 \mathrm{H}, \mathrm{H}-6 \mathrm{Ar}, J_{1}=1.2 \mathrm{~Hz}, J_{1}=1.6 \mathrm{~Hz}, J_{2}=7.2 \mathrm{~Hz}$, $\left.J_{2}=7.4 \mathrm{~Hz}, J_{3}=7.6 \mathrm{~Hz}\right), 7.73-7.77(\mathrm{dt}, 1 \mathrm{H}, \mathrm{H}-7 \mathrm{Ar}$, $J_{1}=1.2 \mathrm{~Hz}, \quad J_{1}=2.0 \mathrm{~Hz}, \quad J_{1}=1.6 \mathrm{~Hz}, \quad J_{2}=7.4 \mathrm{~Hz}$, $\left.J_{2}=7.6 \mathrm{~Hz}, J_{2}=7.5 \mathrm{~Hz}\right), 7.81-7.83(\mathrm{dt}, 1 \mathrm{H}, \mathrm{H}-4 \mathrm{Ar}$, $\left.J_{1}=1.2 \mathrm{~Hz}, J_{2}=7.6 \mathrm{~Hz}\right), 8.20-8.23(\mathrm{dd}, 1 \mathrm{H}, \mathrm{H}-5 \mathrm{Ar}$, $\left.J_{1}=1.2 \mathrm{~Hz}, J_{2}=7.6 \mathrm{~Hz}\right), 8.23-8.25(\mathrm{dd}, 1 \mathrm{H}, \mathrm{H}-8 \mathrm{Ar}$, $\left.J_{1}=1.2 \mathrm{~Hz}, J_{2}=7.6 \mathrm{~Hz}\right),{ }^{13} \mathrm{C} \mathrm{NMR}\left(\mathrm{CDCl}_{3}, 100 \mathrm{MHz}\right) \delta$ $14.1 ; 48.3\left(\mathrm{CH}_{2}\right) ; 116.8,120.40,126.9,127.47,127.82$, $128.5,133.2,133.8,134.0,134.5,135.3,135.4(\mathrm{CH}, \mathrm{Ar})$; 182.6, $184.7(2 \mathrm{C}=\mathrm{O}, \mathrm{Ar})$; Maldi-Tof $m / z, 280.1[\mathrm{M}+\mathrm{H}]^{+}$, $(\mathrm{MW}=279.333)$; Anal. $\left(\mathrm{C}_{18} \mathrm{H}_{17} \mathrm{NO}_{2}\right)$ : Calcd. C, 77.40; $\mathrm{H}$, 6.13; N, 5.01; found C, 77.42; H, 6.15; N, 5.01; Purity (HPLC): $99.8 \% . t_{\mathrm{R}}=13.48 \mathrm{~min}$.

$\mathrm{UV}-\mathrm{Vis}$ spectrophotometry

All UV-Vis spectra were recorded in 290-650-nm range on a Perkin Elmer Lambda $650 \mathrm{UV}-\mathrm{V}$ is double beam spectrophotometer with automatic stirrer. 1-cm quartz microcells were used. The concentrations of compounds used for all spectrophotometric measurements were around $1.7 \times 10^{-4}-2.2 \times 10^{-4} \mathrm{M}$. All measurements were performed at $298 \mathrm{~K}$ in acetonitrile.

To obtain the values of dissociation constants of measured compounds $\left(p K_{\mathrm{a}}\right)$, spectrophotometric titration was used: the compounds were dissolved in acetonitrile and titrated with methanesulfonic acid solution. For each point of known $\mathrm{pH}$, the absorption spectrum was recorded.

Scheme 1 Synthesis of

1-(ethylamino)anthraquinone

(AQNHEt)<smiles>O=C1c2ccccc2C(=O)c2c(Cl)cccc21</smiles><smiles>C[C+]CCCC</smiles>

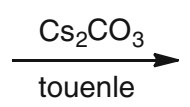<smiles>CCNc1cccc2c1C(=O)c1ccccc1C2=O</smiles>

$(69 \%)$

Scheme 2 Synthesis of 1-(diethylamino)anthraquinone $\left(\mathrm{AQNEt}_{2}\right)$<smiles>O=C1c2ccccc2C(=O)c2c(Cl)cccc21</smiles>

$+$<smiles>CCNCC</smiles>

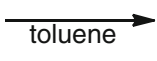<smiles>CCN(CC)c1cccc2c1C(=O)c1ccccc1C2=O</smiles>

(90\%) 
pH measurements were made with a CercoLab system with a $\mathrm{pH}$-meter using a combined glass electrode. The electrode was calibrated in the buffer system of 2,6-dinitrophenol/tetrabutylammonium 2,6-dinitrophenolate in acetonitrile. The resolution of the voltage measurement was $<0.1 \mathrm{mV}$.

To define the number of equilibria present in the studied system, the A-diagrams, which show a relationship between absorbances at two different wavelengths, were analyzed. The theoretical model was fitted to the experimental data presented as a plot of absorbance versus $\mathrm{pH}$.

All calculations were performed with the OriginLab software using the Henderson-Hasselbach equation, based on change in absorption as a function of $\mathrm{pH}$ of the solution [15].

$p K_{\mathrm{a}}=\mathrm{pH}-\log \frac{[\mathrm{B}]}{[\mathrm{BH}]}=\mathrm{pH}-\log \frac{\mathrm{A}_{\lambda}-\mathrm{A}_{\lambda_{\mathrm{BH}}}}{\mathrm{A}_{\lambda \mathrm{B}}-\mathrm{A}_{\lambda}}$

where $\mathrm{B}$ and $\mathrm{BH}$ stand for the compound in its basic and acidic forms, respectively, while $\mathrm{A}_{\lambda \mathrm{B}}$ and $\mathrm{A}_{\lambda \mathrm{BH}}$ denote the absorbance of these forms.

For the evaluation of electrode parameters, the STOICHIO version of the CVEQUID software based on the nonlinear least-squares Gauss-Newton-Marquardt algorithm was used [16-18].

\section{Cyclic voltammetry}

The electrochemical measurements were carried out in a single-compartment, three-electrode cell. The potential was applied with an Autolab potentiostat/galvanostat PGSTAT30 (Eco Chemie B.V., The Netherlands) controlled with the General Purpose Electrochemical System (GPES 4.9) software. All potentials were measured against an Ag/ $\mathrm{AgCl}$ reference electrode with the aqueous silver-silver chloride $(0.1 \mathrm{M} \mathrm{NaCl})$ solution. This reference electrode was separated from the measuring cell by a salt bridge. In all experiments, the solution was deaerated by passing argon. The working electrode was a $0.2-\mathrm{cm}$-diameter glassy carbon electrode, and a platinum wire served as an auxiliary electrode. The investigated solutions consisted of a $0.1 \mathrm{M}$ tetrabutylammoniumperchlorate (TBAP) in acetonitrile as a base electrolyte. All cyclic voltammetry measurements were performed at $\mathrm{RT}\left(\sim 20^{\circ} \mathrm{C}\right)$.

\section{Computational details}

We applied the density functional theory method with Becke's three-parameter hybrid functional (B3LYP) [19$21]$, the $6-31++\mathrm{G}^{* *}[22,23]$ basis set, and the Polarizable Continuum Model (PCM) [24-26] to the acetonitrile solution calculations. All the geometries were fully optimized without any geometric constraints, and the analysis of harmonic frequencies demonstrated that all these were geometrically stable (all force constants were positive). The Gibbs free energies of particular reactions $(\Delta G \mathrm{~s})$ were electronic energy change $(\Delta E \mathrm{~s})$ corrected for zero-point vibration terms, thermal contributions to energy, the $\mathrm{pV}$ term, and the entropy term. These terms were calculated in the rigid rotor-harmonic oscillator approximation for $\mathrm{T}=298 \mathrm{~K}$ and $\mathrm{p}=1 \mathrm{~atm}$ [27]. Relative free energy change $\Delta \Delta G$ was defined as the difference between $\Delta G$ of particular aminoanthraquinone derivative and the lowest $\Delta G$ for the same reaction type.

All calculations have been carried out with the GAUSSIAN09 [28] code. The images of the molecules were plotted using the GaussView package [29].

\section{Results and discussion}

\section{UV-Vis Spectrophotometry}

Two absorption bands, in the range of 290-650 nm, occur in the UV-Vis spectra of anthraquinone derivatives containing the amino substituent at position 1 [13, 14]. The band at around $320 \mathrm{~nm}$ is associated with the benzenoid character of the molecule $[13,14]$. The second absorption maximum occurs around $500 \mathrm{~nm}$, which is due to the presence of amine nitrogen atom at position 1 of anthraquinone (see Fig. 2).

In methanol, Peter and Sumner observed a bathochromic shift of benzenoid band with the increase of its intensity for the AQ derivatives with an electron-donating amino substituent [12]. A similar effect has been found in our experiments, where the replacement of the amino group with the ethylamino or diethylamino one causes the bathochromic shift of the benzenoid absorption band with the

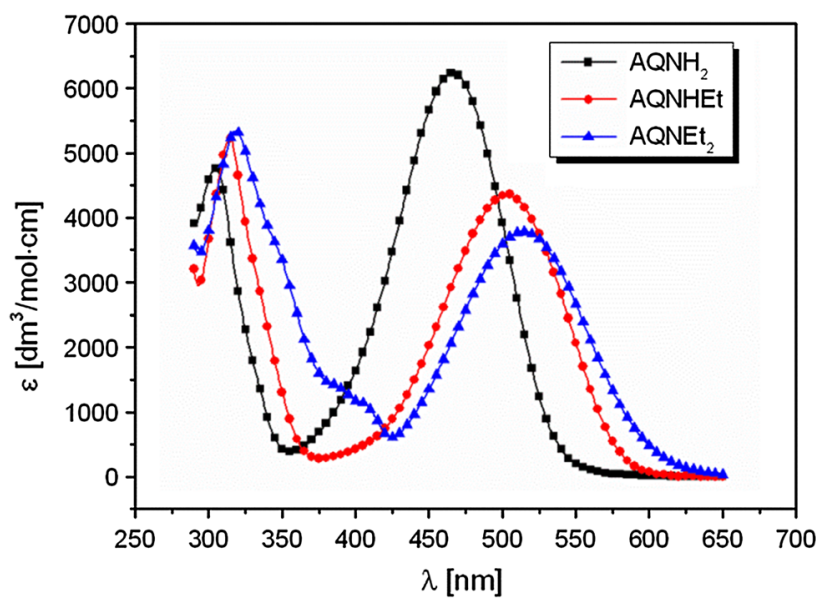

Fig. 2 The absorption spectra of anthraquinone derivatives $\mathrm{AQNH}_{2}$, $\mathrm{AQNHEt}$, and AQNEt $t_{2}$ in acetonitrile 
Table 1 Logarithm of molar absorption coefficient $(\log \varepsilon)$, negative of logarithm of acid dissociation constant $\left(p K_{\mathrm{a}}\right)$ with uncertainty, and experimental $\left(\Delta \Delta G_{\text {exp }}\right)$ and theoretical $\left(\Delta \Delta G_{\text {theor }}\right)$ relative Gibbs free energy changes for the reaction (5) for anthraquinone derivatives in acetonitrile

\begin{tabular}{llllllll}
\hline Compound & $\lambda_{\max }(\mathrm{nm})$ & $\log \varepsilon_{\max }$ & $\lambda_{\max }(\mathrm{nm})$ & $\log \varepsilon_{\max }$ & $p K_{\mathrm{a}}$ & $\Delta \Delta G_{\exp }(\mathrm{kcal} / \mathrm{mol})$ & $\Delta \Delta G_{\text {theor }}(\mathrm{kcal} / \mathrm{mol})$ \\
\hline $\mathrm{AQNH}_{2}$ & 466 & 3.79 & 305 & 3.68 & $8.01 \pm 0.01$ & 0.00 & 0.00 \\
AQNHEt & 504 & 3.64 & 314 & 3.72 & $8.66 \pm 0.01$ & 0.89 & 2.16 \\
AQNEt $_{2}$ & 514 & 3.58 & 319 & 3.72 & $14.93 \pm 0.01$ & 9.44 & 15.58 \\
\hline
\end{tabular}

concomitant increase of its molar absorption coefficient. An increase in the intensity of the band is associated with an increase in the share of benzenoid electronic transitions at the expense of the quinonoid ones [13]. Likewise, the band in the visible region of the spectrum moves to longer wavelength region and decreases its intensity with the increasing electron-donating character of the amino substituent (see Fig. 1), which is evidenced by the values of absorption maximum and the logarithm of molar absorption coefficient, which vary from $\lambda=466 \mathrm{~nm}, \log \varepsilon=3.79$ for compound $\left(\mathrm{AQNH}_{2}\right)$ to $\lambda=504 \mathrm{~nm}, \log \varepsilon=3.64$; and $\lambda=514 \mathrm{~nm}, \log \varepsilon=3.58$ for compounds AQNHEt and $\mathrm{AQNEt}_{2}$, respectively (see Table 1).

The addition of the excess of methanesulfonic acid to the acetonitrile solution of the investigated compounds causes disappearance of the long wavelength band and small shifts of the short wavelength absorption $(\sim 300 \mathrm{~nm})\left[\left(\mathrm{AQNH}_{2}\right) 20 \mathrm{~nm}\right.$, (AQNHEt) $15 \mathrm{~nm}$, and $\left(\mathrm{AQNEt}_{2}\right) 7 \mathrm{~nm}$. In cases of $\mathrm{AQNH}_{2}$ and AQNHEt, however, it was necessary to use an acid solution of $0.1 \mathrm{M}$ to observe a complete disappearance of the long wavelength band, while for $\mathrm{AQNEt}_{2}$, the equimolar amount of acid was sufficient.

In order to determine the number of acid-base equilibria present in acetonitrile solution and to measure the acid dissociation constants of the investigated derivatives, $\mathrm{pH}$ spectroscopic titrations were performed. The example of titration curve is presented for AQNHEt (see Fig. 3). The respective data for the remaining compounds are shown in Supporting Information (SI; Figures S1 and S3).

The change of absorbance with $\mathrm{pH}$ shows one equivalence point (see Fig. 4a), and the A-diagram represents a straight line (see Fig. 4b).

In addition, there are two isosbestic points (for AQNHEt at 323 and $377 \mathrm{~nm}$, see Fig. 3). The analysis of the obtained spectroscopic data shows that in the acetonitrile solution of AQNHEt, only one acid-base equilibrium is present. Hence, the following reaction model has been used to obtain the dissociation constants:

$$
\begin{aligned}
& \mathrm{HB}^{+} \rightleftarrows \mathrm{B}+\mathrm{H}^{+} \\
& K_{\mathrm{a}}=\frac{[\mathrm{B}]\left[\mathrm{H}^{+}\right]}{\left[\mathrm{HB}^{+}\right]}
\end{aligned}
$$

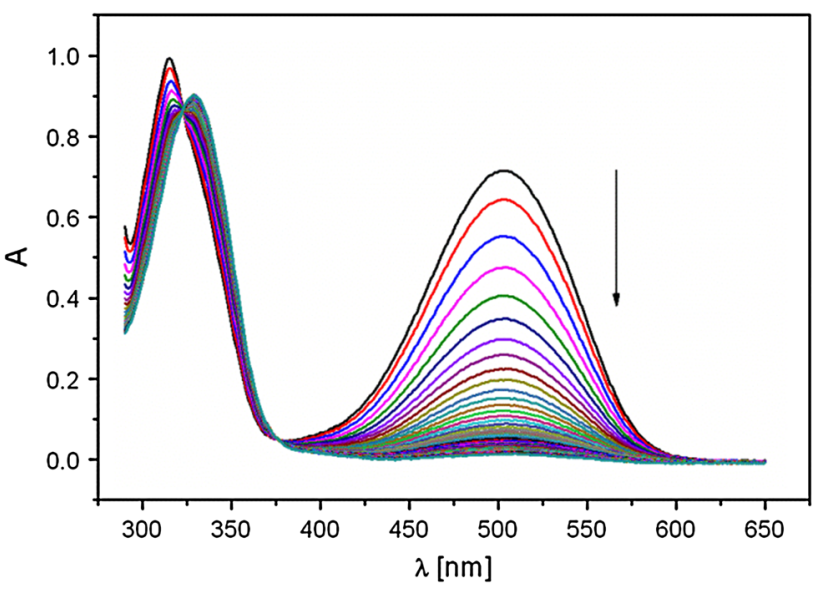

Fig. 3 Spectrophotometric titration of AQNHEt (concentration of $1.79 \times 10^{-4} \mathrm{M}$ ) in the $\mathrm{pH}$ range of $7.5-13.5$ in acetonitrile. The arrow indicates the change in absorbance during titration
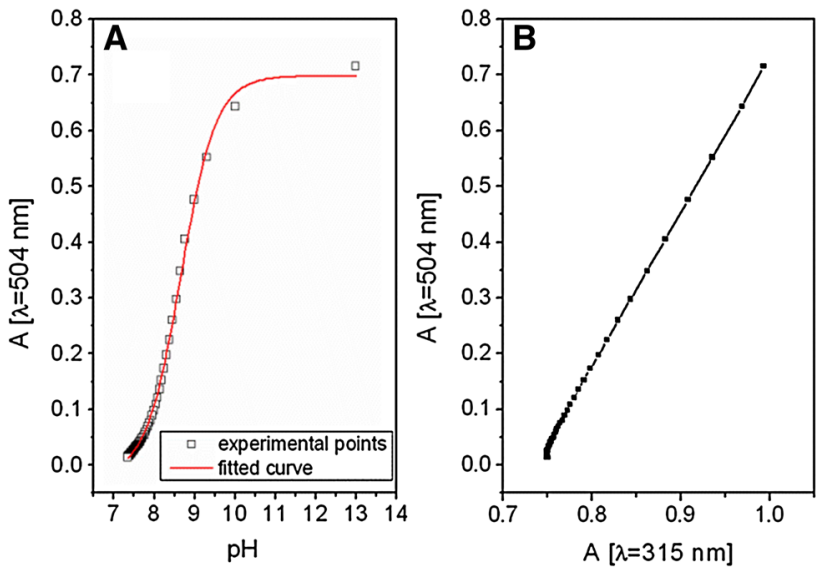

Fig. 4 Fitting of the Henderson-Hasselbach equation to the absorption changes $(\lambda=504 \mathrm{~nm})$ with $\mathrm{pH}$ for AQNHEt (a), and the respective A-diagram (b)

where $\mathrm{B}$ stands for a compound in the base form and $\mathrm{HB}^{+}$ denotes its acidic form.

The $p K_{\mathrm{a}}$ values for the $\mathrm{AQNH}_{2}$ and $\mathrm{AQNHEt}$ derivatives differ slightly, while that for $\mathrm{AQNEt}_{2}$ is much higher (see Table 1), indicating, thus, a higher basicity of $\mathrm{AQNEt}_{2}$ compared with the other two. These values vary from 8.01 
for $\mathrm{AQNH}_{2}$ and 8.65 for AQNHEt to 14.93 in the case of $\mathrm{AQNEt}_{2}$. One can wonder why AQNEt ${ }_{2}$ is a much stronger base then monoethylamino- or unsubstituted aminoanthraquinones. Basic organic chemistry suggests that the increase in the number of alkyl substituents on amine nitrogen is associated with the increase of its basicity. Indeed, the $p K_{\mathrm{a}}$ of AQNHEt is larger, by $0.7 p K$ unit, than that of $\mathrm{AQNH}_{2}$ (see Table 1). Introducing, the second ethyl substituent to the amine function, however, leads to a dramatic increase in the aminoanthraquinone basicity. In other words, the $p K_{\mathrm{a}}$ of $\mathrm{AQNEt}_{2}$ is by ca $6 p K$ units larger than that of AQNHEt. The results of our QM calculations account well for the experimental findings. In Table 1, the relative differences between the free energies of the basic and acidic forms of the studied aminoanthraquinones are compared. The experimental and B3LYP data remain in a qualitative accordance, and quantitatively they differ by no more than $1.3-6.1 \mathrm{kcal} / \mathrm{mol}$ (see Table 1).

Moreover, in Fig. 5, the geometries of the neutral aminoanthraquinones and their protonated counterparts are displayed. These structures demonstrate why only small difference in basicity is observed for $\mathrm{AQNH}_{2}$ and $\mathrm{AQNHEt}$, whereas the substituent effect is much more pronounced for $\mathrm{AQNEt}_{2}$. First, note that for both $\mathrm{AQNH}_{2}$ and AQNHEt, the addition of proton does not change the topology of the internal hydrogen bond present in the neutral molecule (cf. structures A and B in Fig. 5). On the other hand, the presence of two bulky ethyl substituents in $\mathrm{AQNEt}_{2}$ brings about rotation of the amine group by ca 40 degrees (see $\mathrm{C}$ in Fig. 5), which prevents the coupling of the lone pair on the amine nitrogen with the aromatic system of anthraquinone $\pi$-bonds that make the $\mathrm{AQNEt}_{2}$ lone pair better accessible to protonation than that in $\mathrm{AQNH}_{2}$ or AQNHEt. Moreover, due to the lack of amine hydrogens, there is no stabilizing hydrogen bond in the neutral $\mathrm{AQNEt}_{2}$ (see C in Fig. 5), while such a hydrogen bond is formed in the protonated species (see $\mathrm{C}$ in Fig. 5), which greatly stabilizes the latter form and significantly increases the basicity of the considered derivative (see Table 1).

\section{Cyclic voltammetry}

The examined anthraquinone derivatives are electrochemically reduced within a typical two-step reduction process as is usually observed for quinones [3]. For $\mathrm{AQNH}_{2}$ and AQNHEt, the same value of the first reduction peak was observed, $E_{\mathrm{pa}}^{1}=-1.088 \mathrm{~V}$, while the second one shows slight variations as $E_{\mathrm{pc}}^{2}=-1.581$ and $-1.553 \mathrm{~V}$, respectively (see Table 2).

Again in case of AQNEt 2 , significant differences in electrochemical behaviors with respect to the remaining compounds are observed. $E_{\mathrm{pc}}^{1}$ reduction peak is slightly shifted toward more negative potential values $\left(E_{\mathrm{pc}}^{1}=\right.$
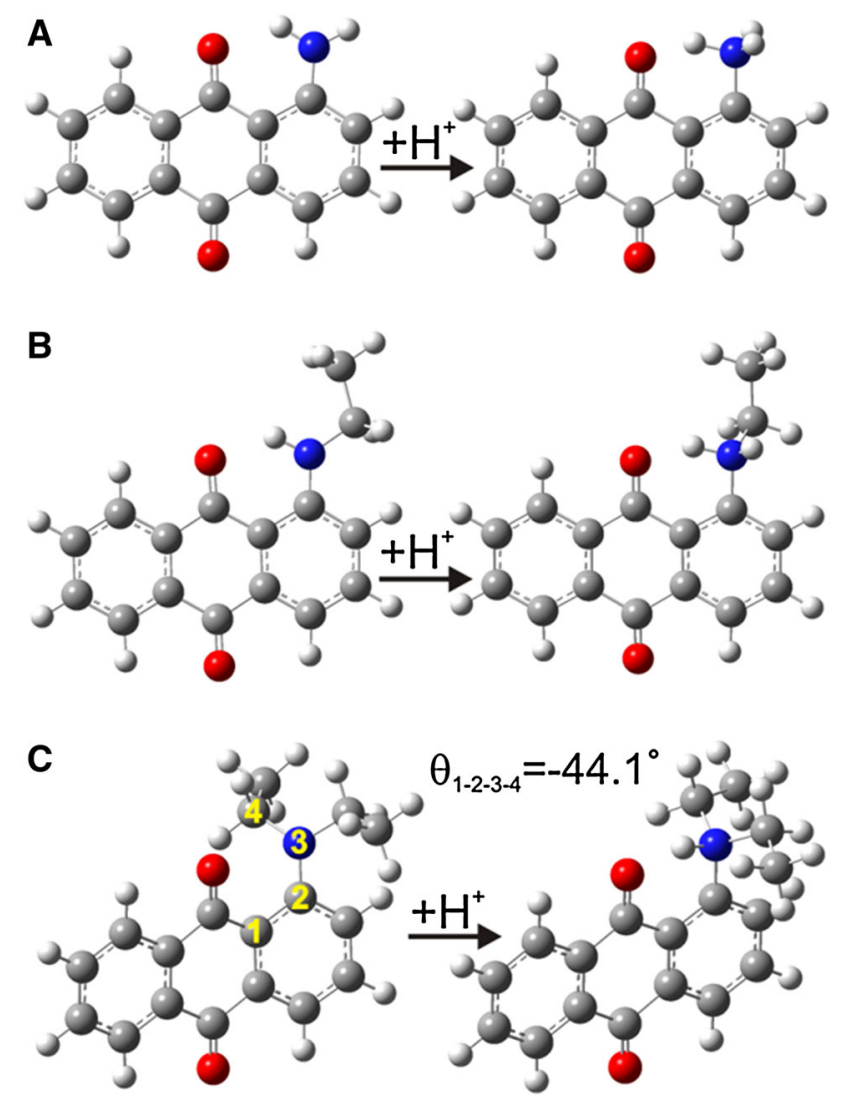

Fig. 5 Neutral and protonated forms of $\mathrm{AQNH}_{2}$ (a), AQNHEt (b), and $\mathrm{AQNEt}_{2}(\mathbf{c})$, calculated at the B3LYP/6-31 ++G(d, p) level in acetonitrile. $\Theta_{1-2-3-4}$ denotes the dihedral angle defined by the atoms no $1,2,3$, and 4

$-1.134 \mathrm{~V})$, and the second reduction peak $E_{\mathrm{pc}}^{2}$ is clearly moved (about $0.1 \mathrm{~V}$ ) in the positive potential direction (Table 2). The main differences arise in the anodic curve (Fig. 6).

In the cyclic voltammograms of $\mathrm{AQNEt}_{2}$, the second anodic process almost vanishes. In the anodic part related to the first reduction process, $E_{\mathrm{pc}}^{1}$, a dual peak appears, with the $E_{\mathrm{pa}}^{1}$ and $E_{\mathrm{pa}}^{3}$ potentials (see Fig. 6; Table 2). Moreover, the anodic response does not significantly change regardless of whether the potential of the electrode reaches the value at which the formation of $\mathrm{Q}^{-}$or $\mathrm{Q}^{2-}$ occurs.

In order to explain why the three relatively similar compounds differ in the mechanisms of reduction and oxidation processes in the acetonitrile solution, additional cyclic voltammetry experiments were performed. All the above described facts emphasize the importance of basicity. On the other hand, different acid-base characteristics should not be relevant for polar aprotic medium such as acetonitrile. However, one should remember that even a dry acetonitrile contains traces of water which can react with a substance of acidic or basic character [30]. Therefore, these additional cyclic voltammetry experiments were carried out in the presence of controlled concentration of water. 
Table 2 The values of the reduction potential peak $\left(E_{\mathrm{pc}}\right)$, oxidation potentials peak $\left(E_{\mathrm{pa}}\right)$, and the difference between the potentials of reduction and oxidation peaks of the studied electrode processes

\begin{tabular}{llllllrr}
\hline Compound & $E_{\mathrm{pc} 1}$ & $E_{\mathrm{pa} 1}$ & $\Delta E_{1}$ & $E_{\mathrm{pc} 2}$ & $E_{\mathrm{pa} 2}$ & $\Delta E_{2}$ & $E_{\mathrm{pa} 3}$ \\
\hline $\mathrm{AQNH}_{2}$ & -1.088 & -1.004 & 0.084 & -1.581 & -1.497 & 0.084 \\
$\mathrm{AQNHEt}$ & -1.088 & -0.994 & 0.094 & -1.553 & -1.469 & 0.084 \\
$\mathrm{AQNEt}_{2}$ & -1.134 & -1.050 & 0.084 & -1.469 & $\sim-1.3^{\mathrm{a}}$ & $\sim 0.17^{\mathrm{a}}$ & -0.780 \\
\hline
\end{tabular}

All values in $\mathrm{V}$

a The approximate value due to the peak shape

The addition of water to the acetonitrile solution of the investigated compounds resulted in a substantial change in cyclic voltammograms. An example of cyclic voltammograms for AQNHEt in the presence of increasing concentrations of water is shown in Fig. 7.

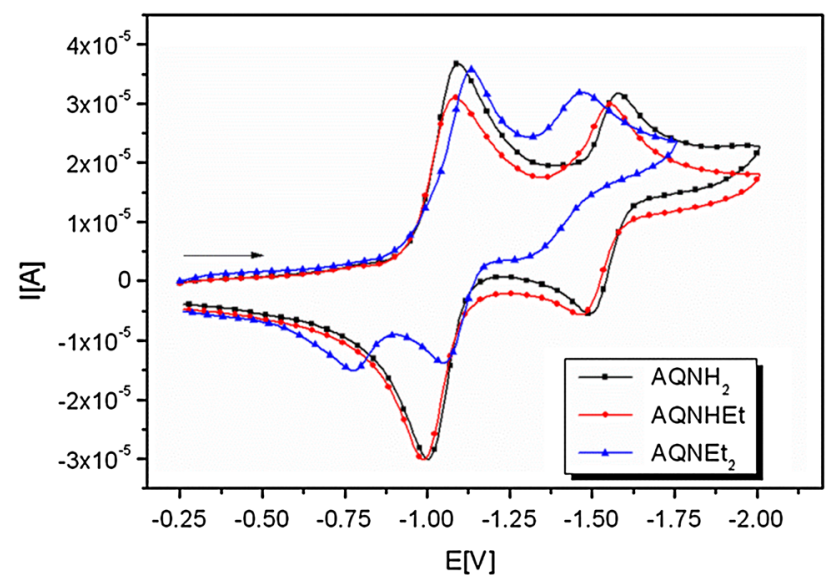

Fig. 6 Cyclic voltammograms of anthraquinone derivatives (concentration of $1.0 \mathrm{mM}$ ) in acetonitrile with $0.1 \mathrm{M} \mathrm{Bu}_{4} \mathrm{NClO}_{4}, v=0.1 \mathrm{~V} / \mathrm{s}$. Arrow indicates initial potential and initial scan direction

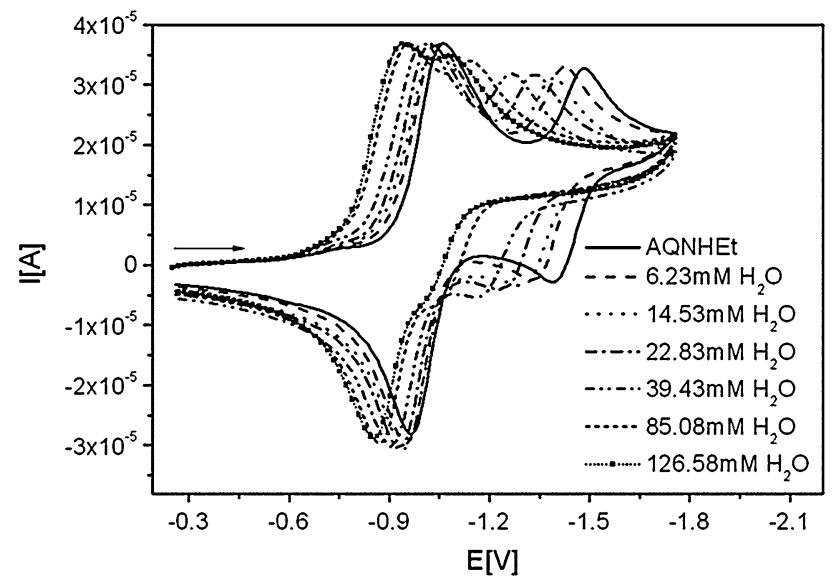

Fig. 7 Cyclic voltammograms of $0.95 \mathrm{mM}$ AQNHEt in the presence of increasing concentrations of water $(0.0-0.126 \mathrm{M})$ in acetonitrile with $0.1 \mathrm{M} \mathrm{Bu}_{4} \mathrm{NClO}_{4}, v=0.1 \mathrm{~V} / \mathrm{s}$. Arrow indicates initial potential and initial scan direction
With the increase of water concentration, the reduction and oxidation potentials for the first process shifted toward more positive values. However, the reversibility of the process expressed as $\Delta E=E_{\mathrm{pc}}^{1}-E_{\mathrm{pa}}^{1}$ and the cathode and anode currents height, $\mathrm{i}_{\mathrm{pc}}^{1}, \mathrm{i}_{\mathrm{pa}}^{1}$, did not change with water content. The second step reduction/oxidation potential $\left(E_{\mathrm{pc}}^{2}, E_{\mathrm{pa}}^{2}\right)$ moves stronger to positive potentials than the first one.

A completely different situation occurs in case of AQ$\mathrm{NEt}_{2}$. Increasing the concentration of water results in the disappearance of reduction peak $E_{\mathrm{pc}}^{2}$ (see Fig. 8).

A gradual increase of water concentration causes a strong increase in the reduction peak $E_{\mathrm{pc}}^{1}$ current and shifts it toward more positive potential values. Moreover, the presence of water brings about a gradual increase of the peak $E_{\mathrm{pa}}^{3}$ and total disappearance of the peak $E_{\mathrm{pa}}^{1}$ in the anodic part of the voltammogram curve. Finally, under high concentration of water (over $18 \mathrm{mM}$ ), a significant change in the reduction process occurs, which suggests the product of the reduction undergoes a further chemical transformation.

The differences observed for the electroreduction of the investigated quinones might be related to the difference in the basicity of their reduced form. Indeed, the

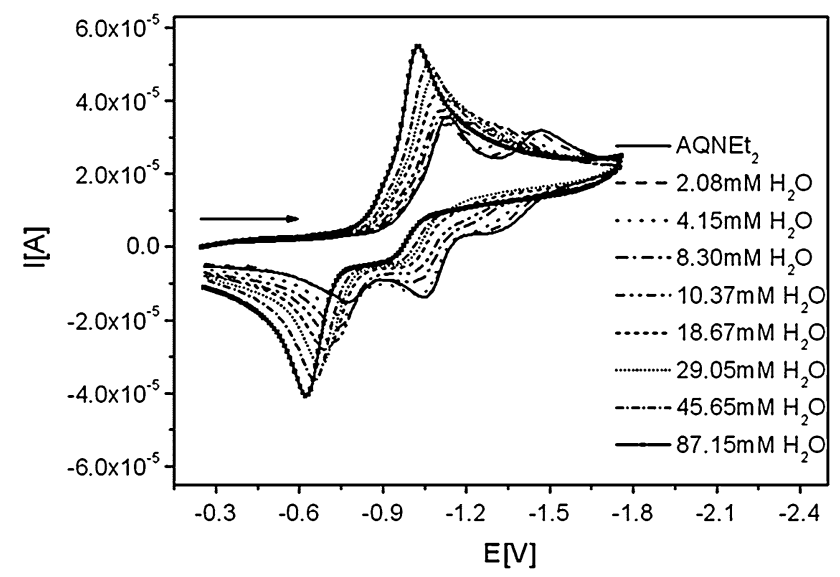

Fig. 8 Cyclic voltammograms of $1.01 \mathrm{mM} \mathrm{AQNEt}_{2}$ in the presence of increasing concentrations of water $(0.0-0.087 \mathrm{M})$ in acetonitrile with $0.1 \mathrm{M} \mathrm{Bu}_{4} \mathrm{NClO}_{4}, v=0.1 \mathrm{~V} / \mathrm{s}$. Arrow indicates initial potential and initial scan direction 
electrochemical experiments with the controlled amount of water indicate clearly that the usually observed EE mechanism (eq. 2 and 3) is modified, when the content of water is increased. This effect is conspicuously visible for AQ$\mathrm{NEt}_{2}$ and suggests that the EE mechanism is converted to the ECE one. The dianion $\mathrm{Q}^{2-}$ formed in the second reduction process is probably capable of reacting even with traces of water (eq. 7). The hydroxyl ion formed in the latter reaction can subsequently interact with the quinone molecule (eq. 8) resulting in the third oxidation peak $E_{\text {pa. }}^{3}$.

$\mathrm{Q}^{2-}+\mathrm{H}_{2} \mathrm{O} \rightleftarrows \mathrm{HQ}^{-}+\mathrm{OH}^{-}$

$\mathrm{Q}+\mathrm{OH}^{-} \rightarrow \mathrm{C}^{-}$

$2 \mathrm{Q}+2 \bar{e}+\mathrm{H}_{2} \mathrm{O} \rightarrow \mathrm{HQ}^{-}+\mathrm{C}^{-}$

Interestingly, the third oxidation peak for $\mathrm{AQNEt}_{2}$ is registered even before its dianion is electrochemically generated. In order to observe $E_{\mathrm{pa}}^{3}$, it is sufficient to polarize the working electrode to a potential characteristic for the first reduction process. The explanation of this phenomenon can be a disproportionation reaction of anion radical created at the $E_{\mathrm{pc}}^{1}$ potential (eq. 10).

$2 \mathrm{Q}^{-\bullet} \rightarrow \mathrm{Q}^{2-}+\mathrm{Q}$

$\mathrm{Q}^{2-}$ will then react according to the scheme comprising reactions (7-9), forming ultimately a product $C$ that gives rise to the $E_{\mathrm{pa}}^{3}$ signal during the oxidation phase of cyclic voltammetry. Hence, the formation of the product $\mathrm{C}$ without producing dianion electrochemically can be considered as an indirect proof of the postulated ECE mechanism.

The results of our B3LYP calculations fully support the conclusions formulated in the previous paragraph. Table 3 gathers thermodynamic characteristics for steps 7-9. In $\Delta G$ calculations, entropy was limited to its vibrational contribution since in the condensed phase, translations and rotations are almost completely hindered. Although one can note only tiny differences between the thermodynamic stimuli for the total process (step 9) involving particular aminoanthraquinones, the characteristics for steps 7 and 8 are pretty much in line with the experimental observations. Indeed, the energy and free energy of proton transfer (PT) between water and an aminoanthraquinone dianion are negative only for $\mathrm{AQNEt}_{2}$, while they are substantially positive for the remaining derivatives. Thus, only the $\mathrm{AQNEt}_{2}$ dianion is able to react spontaneously with water. In a subsequent step, the hydroxyl anions may react with the neutral $\mathrm{AQNEt}_{2}$ molecules forming a gemdiol type species (see Fig. 9).

In fact, the electrochemical reduction of quinones has already been a subject of Lehman and Evans studies [10] that suggested the $\mathrm{Q}^{2-}$ dianion formed in the second step (eq. 3) may react with even a trace amount of water present in acetonitrile, leading to the hydroxyl ion, $\mathrm{OH}^{-}$(eq. 7). According to those researchers, the reaction product (C) (eq. 8) is a gemdiol which results from the hydroxyl anion addition to one of the carbonyl carbons of benzoquinone (In Fig. 9, the most stable product of $\mathrm{OH}^{-}$addition to the carbonyl group of the studied aminoanthraquinones are depicted). As demonstrated by the energetic characteristics gathered in Table 3, the thermodynamic stimulus for the formation of a gemdiol product is indeed negative, which makes this reaction probable as far as thermodynamics is concerned.

According to the proposed model, the product of the electrochemical reaction $\mathrm{AQNEt}_{2}$ transformed by a chemical reaction $(\mathrm{C}$; eq. 8$)$ is then further oxidized at the $E_{\mathrm{ac}}^{3}$ potential. Hence, the proposed mechanism can be defined as the ECE one. In cases of the $\mathrm{AQNH}_{2}$ and AQNHEt compounds, the basicity values of their neutral (Table 1) and reduced forms are substantially lower than that of the $\mathrm{AQNEt}_{2}$ derivative. Indeed, the second reduction process is quasi-reversible, which suggests that there is no chemical reaction of dianion with water in solutions containing $\mathrm{AQNH}_{2}$ or AQNHEt. Interactions between $\mathrm{AQNH}_{2} /$

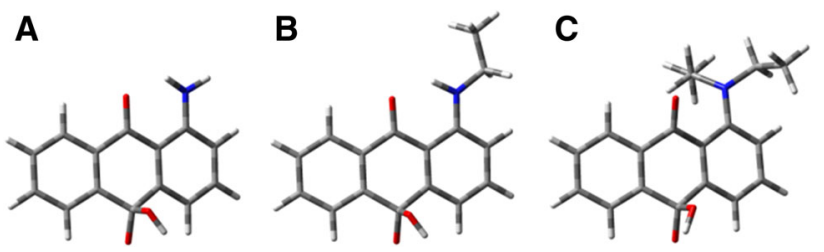

Fig. 9 Gemdiol-type products originated from $\mathrm{AQNH}_{2}(\mathbf{a}), \mathrm{AQNHEt}$ (b), and $\mathrm{AQNEt}_{2}$ (c)

Table 3 Thermodynamic characteristics of ECE mechanism in the presence of water, calculated at the B3LYP/6-31 ++G(d, p) level, in an acetonitrile solution

\begin{tabular}{|c|c|c|c|c|c|c|}
\hline & \multicolumn{2}{|l|}{$\mathrm{AQNH}_{2}$} & \multicolumn{2}{|l|}{ AQNHEt } & \multicolumn{2}{|l|}{$\mathrm{AQNEt}_{2}$} \\
\hline & $\Delta E$ & $\Delta G$ & $\Delta E$ & $\Delta G$ & $\Delta E$ & $\Delta G$ \\
\hline $\mathrm{Q}^{2-}+\mathrm{H}_{2} \mathrm{O} \rightarrow \mathrm{QH}^{-}+\mathrm{OH}^{-}$ & 6.04 & 5.93 & 5.81 & 5.96 & -6.97 & -6.25 \\
\hline $\mathrm{Q}+\mathrm{OH}^{-} \rightarrow \mathrm{C}^{-}$ & -3.63 & -3.91 & -3.48 & -3.57 & -3.47 & -3.86 \\
\hline $2 \mathrm{Q}+2 \bar{e}+\mathrm{H}_{2} \mathrm{O} \rightarrow \mathrm{HQ}^{-}+\mathrm{C}^{-}$ & -134.61 & -137.27 & -134.32 & -137.71 & -143.87 & -145.64 \\
\hline
\end{tabular}

All values in $\mathrm{kcal} / \mathrm{mol}$ 
AQNHEt and the water molecules lead to the formation of molecular complexes (associates) only and the electrochemical processes proceed for these two systems according to the EE mechanism. These water complexes probably facilitate the reduction of anion radical to dianion, which results in shifting the second reduction peak, $E_{\mathrm{pc}}^{2}$, toward the first one (see Fig. 7).

\section{Conclusions}

Spectroscopic, electrochemical, and quantum-chemical studies were carried out to determine basicity and electrochemical behavior of 1-aminoanthraquinone and its ethyl derivatives in acetonitrile solutions. We found out that the basicity of the studied 1-aminoanthraquinones increases in the following order: $\mathrm{AQNH}_{2} \approx \mathrm{AQN}-$ $\mathrm{HEt}<\mathrm{AQNEt}_{2}$. The difference in basicity values between $\mathrm{AQNH}_{2} / \mathrm{AQNHEt}$ and $\mathrm{AQNEt}$ a $_{2}$ amounts to as much as ca 6 $p K$ units. Such significantly larger $p K a$ for $\mathrm{AQNEt}_{2}$ results from the presence of two ethyl group at the 1-amino substituent, which prevents the formation of an intramolecular hydrogen bond involving the carbonyl group of anthraquinone moiety in the neutral form of the derivative, while making it possible for the protonated species.

A consequence of the increased basicity of $\mathrm{AQNEt}_{2}$ is the increased basicity of its dianion which manifests itself in altering the mechanism of electrochemical processes. Indeed, the AQNHEt derivative, even in the presence of large excess of water, does not produce a reaction product, oxidized during cyclic voltammetry, since the basicity of its dianion is too small to react with water. On the other hand, the dianion of aminoanthraquinone containing tertiary amine group $\left(\mathrm{AQNEt}_{2}\right)$ is a relatively strong base which, reacting with water, produces the hydroxyl radical that in a subsequent chemical process reacts with the neutral $\mathrm{AQNEt}_{2}$ giving a gemdiol-type derivative. The latter species gives rise to an additional oxidation peak on the cyclic voltammogram of $\mathrm{AQNEt}_{2}$.

\section{Supporting Information}

Spectrophotometric titrations, fitting curves and A-diagrams for $\mathrm{AQNH}_{2}$ and $\mathrm{AQNEt}{ }_{2}$

Acknowledgments This study was financed by the State Funds for Scientific Research through National Center for Science grant No. NN204 122640 (T.O.). In addition, this study was also supported by the Polish Ministry of Science and Higher Education via the Grant No. DS/530-8221-D186-13 (J.R.). This research study was supported by the system project "InnoDoktorant - Scholarships for PhD students, Vth edition". Project is co-financed by the European Union in the frame of the European Social Fund. (L.C.). All calculations have been carried out in Wroclaw Center for Networking and Supercomputing (http://www.wcss.wroc.pl), Grant No. 209 (L.C.).

Open Access This article is distributed under the terms of the Creative Commons Attribution License which permits any use, distribution, and reproduction in any medium, provided the original author(s) and the source are credited.

\section{References}

1. Khmel'nitskaya EY, Grigoriev NB, Lyubchanskaya VM, Mukhanova TI, Granik VG (2004) Chem Heterocycl Compd 40:161-165

2. El-Najjar N, Gali-Muhtasib H, Ketola RA, Vuorela P, Urtti A, Vuorela H (2011) Phytochem Rev 10:353-370

3. Patai S (1988) The Chemistry of Quinones Compounds. Wiley, New York, pp 719-758

4. Pankiewicz F, Zöllmer A, Gräser Y, Hilker M (2007) Arch Insect Biochem and Physiol 66:98-108

5. Ganapathy S, Thomas PS, Fotso S, Laatsch H (2004) Phytochemistry $65: 1265-1271$

6. Gupta N, Linschitz H (1997) J Am Chem Soc 119:6384-6391

7. Blankespoor RL, Hsung R, Schutt DL (1988) J Org Chem 53:3032-3035

8. Quan M, Sanchez D, Wasylkiw MF, Smith DK (2007) J Am Chem Soc 129:12847-12856

9. Shamsipur M, Siroueinejad A, Hemmateenejad B, Abbaspour A, Sharghi H, Alizadeh K, Arshadi S (2007) J Electroanal Chem 600:345-358

10. Lehmann MW, Evans DH (2001) J Electroanal Chem 500:12-20

11. René A, Evans DH (2012) J Phys Chem C 116:14454-14460

12. Peters RH, Sumner HH (1953) J Chem Soc 2101-2110. http:// pubs.rsc.org/en/content/articlelanding/1953/JR/jr9530002110

13. Navas AD (1990) J Photochem Photobiol A 53:141-167

14. Ossowski T, Zarzeczańska D, Zalewski L, Niedziałkowski P, Majewski R, Szymańska A (2005) Tetrahedron Lett 46:1735-1738

15. Polster J, Lachmann H (1989) Spectrometric Titrations: Analysis of Chemical Equilibria. VCH, New York

16. Kostrowicki J, Liwo A (1990) Talanta 37:645-650

17. Kostrowicki J, Liwo A (1984) Comput Chem 8:91-99

18. Kostrowicki J, Liwo A (1984) Comput Chem 8:101-105

19. Becke AD (1988) Phys Rev A 38:3098-3100

20. Becke AD (1993) J Chem Phys 98:5648-5652

21. Lee C, Yang W, Parr RG (1988) Phys Rev B 37:785-789

22. Ditchfield R, Hehre WJ, Pople JA (1971) J Chem Phys 54:724-728

23. Hehre WJ, Ditchfield R, Pople JA (1972) J Chem Phys 56:2257-2261

24. Miertuš S, Scrocco E, Tomasi J (1981) Chem Phys 55:117-129

25. Miertuš S, Tomasi J (1982) Chem Phys 65:239-245

26. Cossi M, Barone V, Cammi R, Tomasi J (1996) Chem Phys Lett 255:327-335

27. Wong MH, Kenneth B, Wiberg KB, Frisch M (1991) J Chem Phys 95:8991-8998

28. Frisch MJ, Trucks GW, Schlegel HB, Scuseria GE, Robb MA, Cheeseman JR, Scalmani G, Barone V, Mennucci B, Petersson GA, Nakatsuji H, Caricato M, Li X, Hratchian HP, Izmaylov AF, Bloino J, Zheng G, Sonnenberg JL, Hada M, Ehara M, Toyota K, Fukuda R, Hasegawa J, Ishida M, Nakajima T, Honda Y, Kitao O, Nakai H, Vreven T, Montgomery JA Jr, Peralta JE, Ogliaro F, Bearpark M, Heyd JJ, Brothers E, Kudin KN, Staroverov VN, Kobayashi R, Normand J, Raghavachari K, Rendell A, Burant JC, Iyengar SS, Tomasi J, Cossi M, Rega N, Millam JM, Klene M, 
Knox JE, Cross JB, Bakken V, Adamo C, Jaramillo J, Gomperts R, Stratmann RE, Yazyev O, Austin AJ, Cammi R, Pomelli C, Ochterski JW, Martin RL, Morokuma K, Zakrzewski VG, Voth GA, Salvador P, Dannenberg JJ, Dapprich S, Daniels AD, Farkas Ö, Foresman JB, Ortiz JV, Cioslowski J, Fox DJ (2009) Gaussian 09, revision B.01. Gaussian. Inc, Wallingford
29. Dennington R, Keith T, Millam J (2009) GaussView, version 5. Semichem Inc, Shawnee Mission KS

30. Coetzee JF (1986) Pure \& Appl Chem 58:1091-1104 